\title{
Landslide monitoring of Mentougou Jietai Temple
}

\author{
Hanchuan Dong ${ }^{1, ~ a, ~ L i l i ~ P a n g ~}{ }^{2, b}$ Yue $W^{3, c}$ and Kai Yang ${ }^{4, d}$ \\ ${ }^{1,2,3,4}$ Center for hydrogeology and environmental geology survey,cgs, China

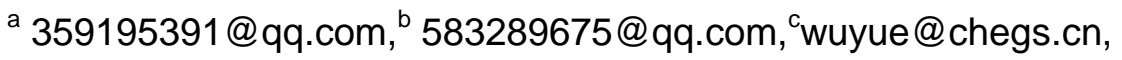 \\ dyangkai@chegs.cn
}

Keywords: Jietai Temple; Landslide; Monitoring; Mentougou

Abstract. Jietai Temple landslide is located in the north wing slope of Ma'an mountain, Mentougou distric to Beijing, and is China's key cultural relics protection units and famous Buddhist temples. According to Jietai Temple landslide formation conditions, predisposing factors, deformation and failure characteristics, stability conditions and trends, etc., using rainfall, soil moisture, surface cracks, deep displacement, groundwater level, groundwater seepage pressure, GPS deformation, geotechnical a variety of monitoring tools stress, long-term professional for Jietai Temple landslide deformation monitoring. Monitoring and analysis showed that construction monitoring network can provide an effective basis for the development of Jietai Temple to master deformed landslide.

\section{Introduction}

Jietai Temple landslide located in northern foot ofMa'anmountain ,yongding town, mentougou district,it is $35 \mathrm{~km}$ from the capital. In September 2004 discovered a very long way cracks from the northeast corner when repairing Qian Fogeruins, its widest point achieve $200 \mathrm{~mm}$ and narrowest point is only $5 \mathrm{~mm}$, ground fissures by the Department, the building appears local sink or crack. There are many shear and subsidence in 108 State Road, the maximumstation achieve 700mm. The northern slope of state road has a crack cross north and South.TheQiuPo village in west of ridge appears subsidencehouses cracking. 2005 Spring ground deformation sudden acceleration, a maximum displacement reached $6 \mathrm{~mm} /$ day, it precarious. In order to curb the continuous deformation and landslide partial resurrection.China Railway Northwest Academy of scientific studies in 2005 led to Jietai Temple landslide governance.Deformed into the monastery in 2009 has been effectively controlled, the basic stability of the landslide, but there are still many landslide risks,there is still ground tensile deformationinside the yard painter and compression space between them did not reach dense state, so the spring rainy season may also exist harmony slight deformation. In addition, the ridge west of the QiuBo village not within the scope of governance, there is a risk, need further treatment.

In order to grasp Jietai Temple landslide creep characteristics, protection of heritage buildings from destruction, Center for hydrogeology and environmental geology survey,cgs,China. It lay landslide monitoring networks to Jietai Temple .

\section{Solution deployment}

Jietai Temple landslide monitoring deployed primarily on the basis of the formation conditions of the landslide induced factors, deformation and failure characteristics, stability conditions and trends, etc $^{[1]}$. 


\section{Monitoring purposes}

According to the landslide formation conditions, predisposing factors, deformation and failure characteristics, stable conditions and trends, etc., using rainfall, soil moisture, surface cracks, deep displacement, groundwater level, groundwater seepage pressure, GPS deformation, rock stress monitoring and information platform management system and other meansto establish ground and underground, outdoor and indoor, full automation of Jietai Temple landslide monitoring networks.

Through professional monitoring, grasp the landslide deformation of development,the landslide deformation can be understand at first time to monastery buildings and important cultural relics are damaged.

\section{Monitoring contents}

The main content of Jietai Temple landslide monitoring include: rainfall monitoring, surface crack monitoring, soil moisture monitoring, deep displacement monitoring, GPS deformation monitoring, monitoring of groundwater levels, groundwater seepage pressure monitoring, stress monitoring of rock mass.

\section{Monitoring program}

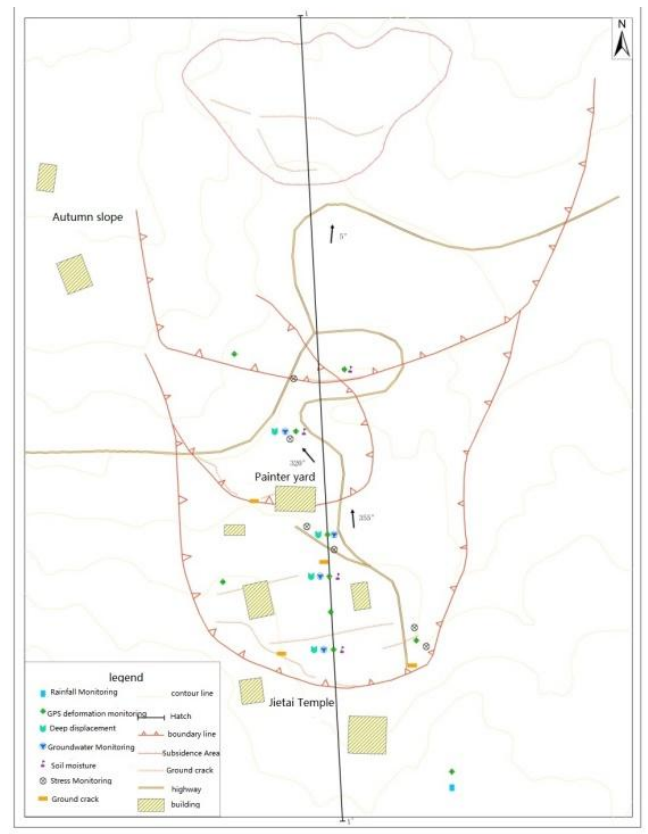

Fig.1The equipment layout of the Jietai Temple Landslidemonitoring

According to the specific circumstances of Jietai Temple landslide monitoring , the equipment mainly laid in and around Jietai Temple, were selected 17 monitoring sites, laid 39 sets of specialized monitoring instruments (Monitoring Deployment Figure 1). Instrument includeing 1 set of rainfall monitoring equipment, 4 sets of surface crack monitoring equipment, four sets of deep displacement meter, four sets of groundwater levels, four sets groundwater seepage pressure, four sets of deep displacement, four sets soil moisture, 12 sets of GPS deformation monitoring and six sets of rock stress monitoring.

\section{Monitoring methods}

According to the monitoring purpose, combined with Jietai Temple landslide deformation and formation characteristics, given its monitoring methods are as follows:

(1) Rainfall Monitoring. Rainfall is an important factor in inducing landslides, deploy a set of integrated rainfall in the southeast corner of the ridge next to Jietai Temple water automatic monitoring stations. 
(2) Soil moisture Monitored. In order to monitor water content about the temple landslide slope of loose soil shallow underground rock and soil, deployed four sets of integrated soil moisture monitoring stations in the region.

(3) Surface crack monitoring. Surface Crack is a form of external representation of the landslide, often distributed around the landslide.

(4) Deep displacement monitoring. Compared with traditional methods, deep slope displacement monitoring have much characters, such as ahead of detecting changes of deep slope displacement , data collection in time, and measurement accuracy is high.

(5) Groundwater level monitoring. Change in groundwater level is one of the factors induced landslides.

(6) Groundwater seepage pressure monitoring. Four sets integrated groundwater seepage pressure monitoring stations have been deployed,so groundwater seepage pressure of Jietai Temple landslide can be monitored.

(7) GPS deformation monitoring ${ }^{[2]-[4]}$.Subsidence and horizontal deformation to occur in different parts of Jietai Temple slope, laid deformed observation network for long-term observation.

(8) Rock stress monitoring ${ }^{[5] \sim[7]}$. When the landslide occurrence, it will produce a stress , by the stress test may also reflect the size of the landslide sliding state. Soil stress monitoring of Jietai Temple using deformation resistance with constant stress monitor cable.

Rock stress monitoring, groundwater level monitoring, groundwater seepage pressure monitoring, deep displacement monitoring device emplaced shown in Figure 2 and Figure 3.

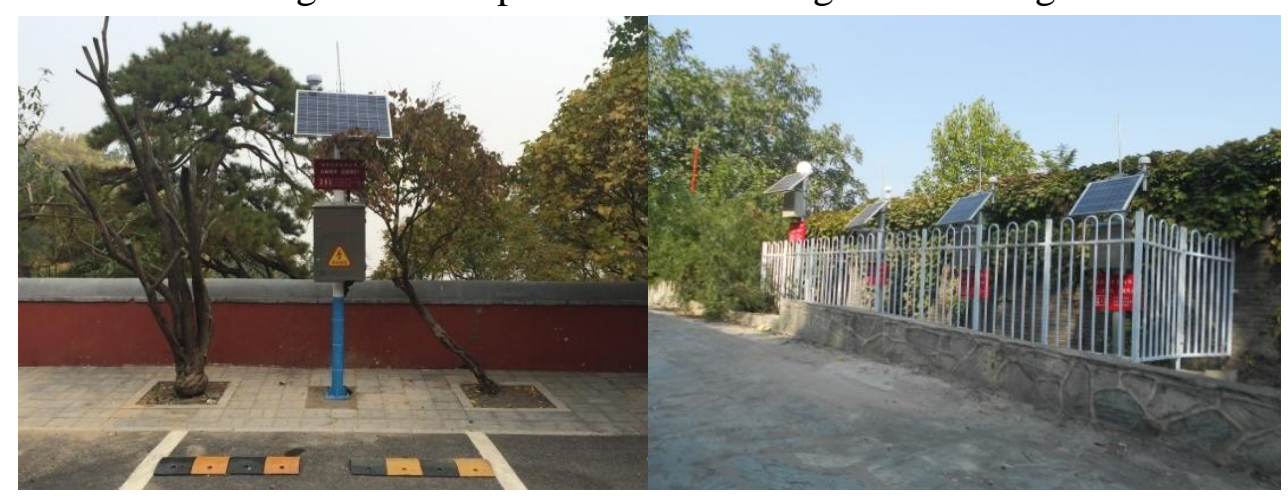

Fig.2 The field of rockstress

Fig.3 The water level,seepage pressure

\section{Monitoring Analysis}

Since the 2004 rainy season, the temple courtyard and surrounding multiple fractures occur, and the emergence of an increasing trend. The selected surface crack monitoring data analysis accordingly. Figure 4 shows the internal courtyard of the monastery north of the painter land subsidence, causing cracking walls, and produces the maximum width of $100 \mathrm{~mm}$ crack in the ground. For this purpose, where layout of a surface crack fracture displacement meter monitor changes. 


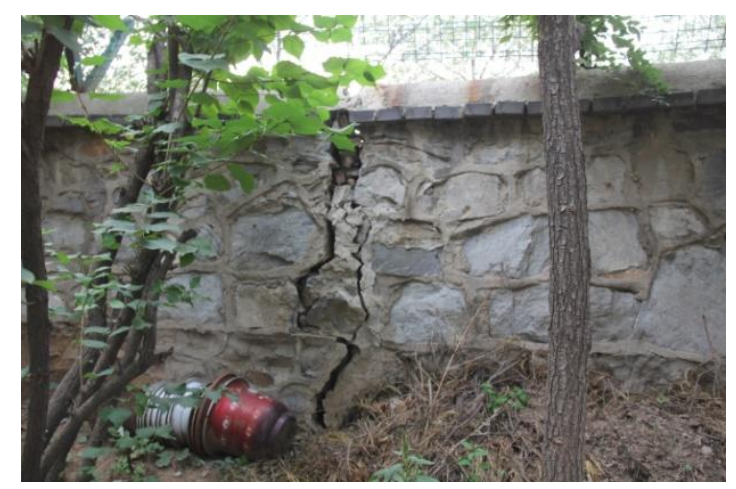

Fig.4 The ground fissure of painteryard

Since September 5, 2014 , crack displacement meter laid begin monitoring, average hourly monitoring. Calculated by the software to filter out the outliers, four crack displacement meters emplaced, monitoring data in Fig.5 since September 5, 2014 to February 5, 2015 .It can be seen form the chart 7 that data are small rise in early installation, is due to instability caused by equipment commissioning phase. Painter yard crack monitoring value increased from $116 \mathrm{~mm}$ to $118 \mathrm{~mm}$, cracks increases $2 \mathrm{~mm}$. It is the early stages that monitor surface cracks of Jietai Temple,and cracks ground level less obvious. through long-term monitoring and multiple spring melt phase, analysis and monitoring data will be more meaningful

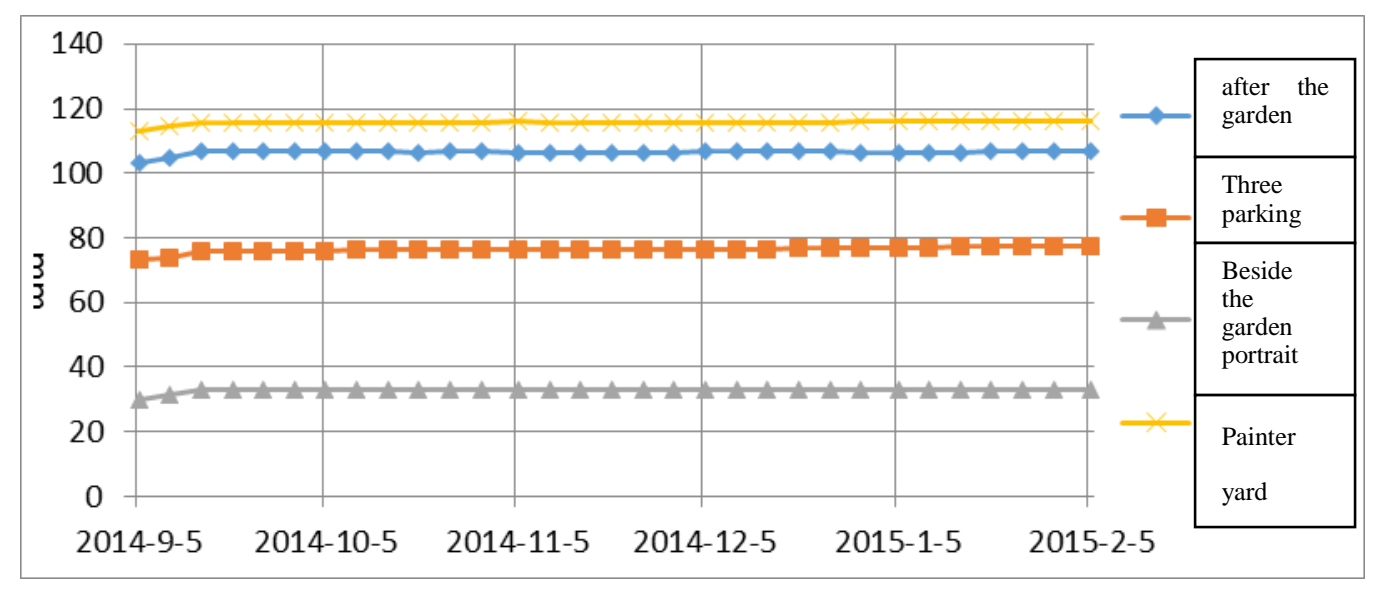

Fig.5 Monitoring of surfacecrack

\section{conclusion}

Through real-time monitoring of of Jietai Temple landslide, Comprehensive analysis of the monitoring concluded that:

(1)After treatment 2005, there is slack belt has a compression space between the blocks. Through this professional deformation monitoring, deformation between the block can be get, rasp the landslide deformation development to provide reliable data, and protect the safety of Jietai Temple artifacts and buildings of great significance.

(2) Through a variety of monitoring methods rainfall, deep displacement, groundwater level, rock stress, the establishment of a ground and underground, outdoor and indoor, full automation of Jietai Temple landslide monitoring networks.

(3) Through specialized monitoring, can provide the basis for dynamic design, construction and evaluation of information engineering effects. At the same time, also provide a reference for future similar large-scale landslide monitoring. 
(4) The landslide monitoring networks without a plurality of spring thaw and long-term monitoring of the rainy season, is still in operation stage, long-term monitoring and analysis needs to be done to ensure the safety of cultural relics and monastery buildings.

\section{Acknowledgements}

This work was financially supported by the National Natural Science Foundation of China (high-speed remote slip instability mechanism and failure process of research Rainfall, 41372332)

\section{Reference}

[1]WANG HongDe,GAO YouLong. Optimal placement of typical landslide monitoring points[J].Jilin University (Earth Science Edition),2013,3(43):858-866.

[2]ZHANG QingZhi,ZHENG WanMo. Application of high-precision GPS systems to dumb Xigaze Danba landslide monitoring and stability analysis[J]. Journal of Engineering Geology,2013,21(2):251-259.

[3]YANG YingHui,CHEN Qiang. Earthquake with seismic deformation field of GPS and InSar adjacent rail smooth correction and refinement off slip inversion[J]. Geophysics,2013,57(5):1462-1476.

[4]WU YanQiang, JIANG ZaiSen, WANG Min,et al.Preliminary results pertaining to coseismic displacement and preseismic strain accumulation of the Lushan MS7.0 earthquake, as reflected by GPS surveying [J]. Chinese Science Bulletin,2013,58(28):3460-3466.

[5]HE ManChao,Guo ZhiBiao. Bolt constant resistance and mechanical properties of large deformation Engineering Application[J]. Rock Mechanics and Engineering,2014,33(7):1297-1308.

[6] ]HE ManChao,HAN Xue. Landslide remote real-time monitoring and forecasting technology and engineering[J]. Heilongjiang Institute of Science and Technology,2012,22(4):337-342.

[7]He Man-Chao, Zhao Jian, Fang Zhi-Jie.First-principles study of atomic and electronicstructures of kaolinite in soft rock [J].Chin. Phys. B,2012,21(3):3460-3466. 